\title{
SUSTANTIVIDAD JURÍDICA DE LA PRETENSIÓN EN EL CÓDIGO DE PROCEDIMIENTO Y JUSTICIA ADMINISTRATIVA PARA EL ESTADO Y LOS MUNICIPIOS DE GUANAJUATO
}

\author{
Legal nature of the claim in the code of procedure and administrative justice for the \\ state an the municipalities of Guanajuato
}

\section{Teresita Rendón Huerta Barrera ${ }^{{ }^{*}}$}

\begin{abstract}
Sumario
Introducción. 1. Sustantividad jurídica de la pretensión en el proceso contencioso administrativo en el Código de Procedimiento y Justicia Administrativa para el Estado y los Municipios de Guanajuato. 2. Sustantividad jurídica y requisitos de admisión de la pretensión, de acuerdo al Código de Procedimiento y Justicia Administrativa para el Estado y los Municipios de Guanajuato. 3. Diferencias entre la pretensión procesal y la demanda.4. Diferencias entre la pretensión procesal y los puntos petitorios.5. Sustantividad jurídica y estructura de la pretensión procesal administrativa. 6. Sustantividad jurídica y clases de pretensión procesal administrativa.7. Conclusiones.
\end{abstract}

Resumen. Esta investigación tiene por objeto establecer la sustantividad jurídica de la pretensión en el proceso contencioso administrativo conforme al Código de Procedimiento y Justicia Administrativa para el Estado y los Municipios de Guanajuato, porque de tal determinación se derivan consecuencias fundamentales, por cuanto delimita subjetiva, objetiva $y$ causalmente el proceso. La acción administrativa, como toda acción procesal, es un derecho subjetivo público, que se ejerce por los gobernados como regla general, y por excepción por las autoridades, tratándose del juicio de lesividad. Para el ejercicio de este derecho, deben concurrir los elementos que el Código de Procedimiento y Justicia Administrativa para el Estado y los Municipios de Guanajuato establece. La acción procesal administrativa va dirigida al juzgador y tiene como contenido una pretensión. La pretensión procesal, afirma la existencia de un derecho público subjetivo de naturaleza administrativa. Tal derecho público subjetivo, entraña siempre una solicitud de pronunciamiento sobre un acto de autoridad que se reputa ilegal. Aparece como un contenido posible de la acción, procesalmente concretado en la demanda, que busca la realización de la pretensión.

Palabras clave: Pretensión procesal administrativa, proceso administrativo, aación administrativa, pretensión procesal y la demanda.

Abstract. This research aims to establish the legal nature of the claim in administrative proceedings under the Code of Procedure and Administrative Justice to the State and the Municipalities of Guanajuato, for of such determination is fundamental consequences follow, as it defines subjective, objective and causal process. Administrative action, like any procedural

\footnotetext{
${ }^{1}$ Doctora en derecho. Miembro del Sistema Nacional de Investigadores. Perfil Promep. Profesora Investigadora del Departamento de Derecho de la División de Derecho, Política y Gobierno del Campus Guanajuato de la Universidad de Guanajuato.
} 
action, is a subjective public right, exercised by the governed as a rule, and exception by the authorities, in the case of the trial of harmfulness. To exercise this right, the elements must be present Procedure Code and Administrative Justice to the State and the Municipalities of Guanajuato states. The administrative procedural action is addressed to the judge and is a content claim. Such a subjective public right, always involves a request that is resolved when an act of authority is deemed illegal.

keywords: administrative claim procedure, administrative process, administrative action, claim procedure and demand

\section{INTRODUCCIÓN}

El problema que dio origen a esta investigación, se centra en determinar cuál es la sustantividad jurídica de la pretensión en el proceso contencioso administrativo en el Código de Procedimiento y Justicia Administrativa para el Estado y los Municipios de Guanajuato, toda vez que esa manifestación de voluntad plasmada en la demanda, pretende del juzgador un fallo congruente y favorable de la litis presentada a su conocimiento. La determinación de tal sustantividad jurídica, tiene consecuencias de primordial valor, por cuanto delimita subjetiva, objetiva y causalmente el proceso.

En el Derecho romano, durante la época del procedimiento formulario, el demandante establecía una fórmula con el pretor, que iniciaba con la intentio, un acto equivalente a la pretensión procesal.

Hoy día, el conjunto de actividades que conforman el proceso administrativo, tienen por objeto la declaración de voluntad por la cual el órgano jurisdiccional, actúa frente a una pretensión determinada. Esta declaración de voluntad, constituye el acto fundamental del proceso contencioso administrativo.

La acción administrativa, como toda acción procesal, es un derecho subjetivo público, que se ejerce por los gobernados como regla general, y por excepción por las autoridades, tratándose del juicio de lesividad. Para el ejercicio de este derecho, deben concurrir los elementos que el ordenamiento jurídico establece. La acción procesal administrativa se dirige al juzgador y tiene como contenido una pretensión. La pretensión procesal, afirma la existencia de un derecho público subjetivo de naturaleza administrativa. Tal derecho público subjetivo, entraña siempre una solicitud de pronunciamiento sobre un acto de autoridad que se reputa ilegal. Aparece como un contenido posible de la acción, procesalmente concretado en la demanda, que busca la realización de la pretensión.

La figura de la pretensión establece las fronteras concretas del contenido del proceso contencioso administrativo y además, condiciona su tramitación y resultado. La pretensión establece el ámbito en el cual, de forma absolutamente necesaria, debe actuar el juzgador. "Unos sujetos, las partes, discutirán acerca de la conformidad de la pretensión con el ordenamiento jurídico; otro, el juez, decidirá acerca de esa conformidad y, en consecuencia, accederá o no a la actuación solicitada."

El acto administrativo se convierte en el primer presupuesto de un proceso articulado técnicamente como un proceso impugnatorio. Sin una decisión administrativa previa, expresa o presunta, no puede haber proceso contencioso-administrativo. 
1. SUSTANTIVIDAD JURÍDICA DE LA PRETENSIÓN EN EL PROCESO CONTENCIOSO ADMINISTRATIVO EN EL CÓDIGO DE PROCEDIMIENTO Y JUSTICIA ADMINISTRATIVA PARA EL ESTADO Y LOS MUNICIPIOS DE GUANAJUATO

Aun cuando doctrinariamente existe coincidencia en señalar que la pretensión procesal es un acto, el problema toma diferentes rumbos cuando se trata de precisar su naturaleza. Así, para Devis Echandía ${ }^{2}$ es un simple acto de voluntad, en tanto Guasp sostiene que es un acto procesal. ${ }^{3}$ Por su parte De la Oliva ${ }^{4}$ lo refiere como "acto dotado de eficacia jurídica", mientras González Pérez asienta que: "La pretensión procesal es un acto, no un derecho, algo que se hace, no algo que se tiene. Es una declaración de voluntad, no una manifestación afectiva, emocional o psicológica del que la formula; pero tampoco es una exteriorización intelectual o declaración de ciencia que se limita a poner de manifiesto la presunta existencia o inexistencia real de una cierta proposición."5 Para Ramírez Arcilla, es "un acto de declaración de voluntad"6 y recientemente, ha sido concebido como "el acto de afirmar la acción".

En efecto, la pretensión es algo que se hace, no algo que se tiene, es una realidad, más no un derecho. El procesalista Francesco Carnelutti, sostiene que "no es un poder sino, por el contrario, es un acto; no se trata de "algo" que alguien tiene, sino de "algo" que alguien hace: una declaración de voluntad. Es una declaración de voluntad, una petición fundada de un sujeto activo ante un órgano jurisdiccional frente a un sujeto pasivo solicitando que se haga algo jurídico." ${ }^{8}$

Por su contenido la pretensión puede ser material, que es aquella intencionalidad frente al demandado; o puede ser pretensión formal o procesal, que es la intencionalidad ante el juez. Ambos tipos se rigen de distinta forma y a esta última, es a la que me referiré en el presente estudio.

La sustantividad jurídica de la pretensión en el proceso contencioso administrativo, se deriva del artículo 255 del Código de Procedimiento y Justicia Administrativa para el Estado y los Municipios de Guanajuato, al referirse a que el actor puede solicitar ante el Tribunal, ya sea la nulidad del acto o resolución impugnado, cuando no haya sido emitido conforme a derecho; el reconocimiento de un derecho amparado en una norma jurídica; y la condena a la autoridad para el pleno restablecimiento del derecho violado, en los términos de la ley respectiva. Consecuentemente, la pretensión procesal en el Código mencionado, es una figura que exige al demandante una manifestación de voluntad, para hacer valer un derecho cuyo fin primordial es apartar de la vida jurídica un acto de autoridad que se estima ilegal y el restablecimiento del derecho conculcado. En la demanda del actor, demandante o también llamado pretendiente, da inicio al proceso ejerciendo una acción mediante la cual pretende que el juzgador provea a su favor, conforme a las probanzas y al derecho.

\footnotetext{
${ }^{2}$ Devis Echandía, H. Nociones Generales de Derecho Procesal Civil, Madrid, 1966. p. 174.

${ }^{3}$ Guasp, J. La pretensión Procesal, Madrid, 1981. p. 66.

${ }^{4}$ De la Oliva, A. Sobre el Derecho a la Tutela Jurisdiccional, Barcelona, 1980. p. 71.

${ }^{5}$ González Pérez. Op. cit. 1987, pp. 152 a 28.

${ }^{6}$ Ramírez Arcilla, C. Teoría de la Acción, Bogotá, 1969. p. 19.

${ }^{7}$ Acosta Estévez, J.B. Pretensión Procesal Administrativa, Barcelona, 1987. p. 28.

${ }^{8}$ Carnelutti, F. Instituciones del Proceso Civil, Buenos Aires, 1962. p. 31.
} 
2. SUSTANTIVIDAD JURÍDICA Y REQUISITOS DE ADMISIÓN DE LA PRETENSIÓN,DE ACUERDO AL CÓDIGO DE PROCEDIMIENTO Y JUSTICIA ADMINISTRATIVA PARA EL ESTADO Y LOS MUNICIPIOS DE GUANAJUATO

Para que una pretensión procesal sea admitida ante el Tribunal de lo Contencioso Administrativo del Estado se requiere:

1. Conforme al artículo 251 del Código de Procedimiento y Justicia Administrativa para el Estado y los Municipios de Guanajuato, se requiere la existencia de un interés jurídico que funde la pretensión, tratándose del actor, cuando es un particular, es necesario que sean afectados sus derechos por un acto o resolución administrativa; y cuando tiene tal carácter la autoridad, en aquellos casos en los que se pida la modificación o nulidad de un acto favorable a un particular, será preciso que tal acto cause lesión al interés público.

2. Que concurran en el acto que se impugna, los siguientes extremos:

- Encontrarse dentro del ámbito del Derecho administrativo;

- Encuadrar en cualquiera de los supuestos que prevé el artículo 20 de la Ley Orgánica del Tribunal de lo Contencioso Administrativo del Estado de Guanajuato; y

- No estar comprendido en alguno de los supuestos de improcedencia que se enumeran en el artículo 261 de la propia ley.

3. Que se formule por quien tiene capacidad para ser parte y procesal.

4. Que quien la formule esté legitimado para deducir la petición en que se concreta y esté dentro de las hipótesis de postulación procesal (artículos 263, 265, 266 de Código relativo).

5. Que se enderece frente a un sujeto con legitimación pasiva.

6. Que su objeto directo no sea solicitar del juzgador declaraciones de principio o doctrinales, o para prevenir agravios futuros o corregir anticipadamente defectos probables que todavía no se han producido.

7. Que no se trate de actos administrativos de ejecución, ya que no son susceptible de impugnación autónoma, salvo que incurran por sí mismos en infracción, no derivada de aquella en que hubiera podido incurrir el acto definitivo.

8. Que se haga por escrito como lo prescribe el mismo Código en su artículo 263, cuyo contenido, conforme al artículo 265 , deberá precisar:

- El nombre del actor o de quien promueva en su nombre; así como el domicilio para recibir notificaciones en el lugar de residencia del Tribunal o del Juzgado respectivo y, en su caso, los autorizados para oír y recibir notificaciones; 
- El acto o resolución que se impugna y, en su caso, la fecha de su notificación o en la que se haya ostentado sabedor del mismo;

- Las autoridades demandadas o el nombre y domicilio del particular demandado;

- El nombre y domicilio del tercero que tenga un derecho incompatible con la pretensión del actor;

- La pretensión intentada en los términos del artículo 255 del Código en cita;

- Los hechos que den motivo a la demanda;

- Los conceptos de impugnación del acto o resolución que se combate; y

- Las pruebas que se ofrezcan.

9. Que se formule por escrito conforme lo señala el artículo 263 del Código aludido, al prescribir que demanda deberá formularse por escrito y presentarse dentro de los treinta días siguientes a aquél en que haya surtido efectos la notificación del acto o resolución impugnado o a aquél en que se haya ostentado sabedor de su contenido o de su ejecución, con las excepciones siguientes:

- Cuando el interesado fallezca durante el término para la interposición de la demanda, el mismo se ampliará hasta por seis meses;

- Cuando se demande la nulidad de un acto favorable al particular, las autoridades podrán presentar la demanda dentro del año siguiente a la fecha en que sea emitido el acto o resolución, salvo que haya producido efectos de tracto sucesivo, caso en el que podrá demandar la modificación o nulidad en cualquier época sin exceder de un año del último efecto, pero los efectos de la sentencia en caso de ser total o parcialmente desfavorable para el particular sólo se retrotraerán al año anterior a la presentación de la demanda; y

- En caso de negativa ficta, la demanda podrá presentarse en cualquier tiempo, mientras no se notifique la resolución expresa.

- La demanda podrá enviarse por correo certificado con acuse de recibo, si el actor tiene su domicilio fuera de la ciudad donde resida el Tribunal o Juzgado, en cuyo caso, se tendrá por presentada en la fecha que fue depositada en la oficina de correos.

10. Que deduzca precisa y directamente ante al Tribunal de lo Contencioso Administrativo o ante el juzgado correspondiente, de acuerdo al propio artículo 263 de referencia; y

11. Que se solicite la nulidad del acto o resolución impugnado, cuando no haya sido emitido conforme a derecho; el reconocimiento de un derecho amparado en una norma jurídica; y la condena a la autoridad para el pleno restablecimiento del derecho violado, en los términos del Código mencionado. 
Aun cuando en el Código de Procedimiento y Justicia Administrativa para el Estado y los Municipios de Guanajuato no se hace la distinción entre la pretensión procesal y la demanda, son conceptos diferentes por las siguientes razones:

1. La instancia se ejercita con la demanda que es el acto por medio del cual se da inicio al proceso y en el que se formula la pretensión, aunque puede haber demanda sin pretensión, caso en el cual, sería imposible la prosecución del juicio.

2. La pretensión engendra y mantiene en vida el proceso; es decir, el proceso existe en tanto se formula y subsiste la pretensión procesal.

3. La demanda ${ }^{9}$ es un acto formal de iniciación del juicio o como le llama González Pérez es el "prius cronológico".

4. La pretensión es el acto esencial y básico del proceso, es su "prius lógico". ${ }^{10}$

\section{DIFERENCIAS ENTRE LA PRETENSIÓN PROCESALY LOS PUNTOS PETITORIOS}

Se impone esta elemental diferenciación, porque ambas figuras implican esencialmente una petición. Tanto la pretensión como los puntos petitorios se contienen en la demanda. No obstante y siendo la pretensión procesal administrativa el instituto jurídico en el que se solicita ante un órgano jurisdiccional, la nulidad o anulación de un acto administrativo, es necesario marcar su diferencia con los puntos petitorios que son aquellas solicitudes de tipo formal que normalmente hace el actor al finalizar el texto de su demanda.

La pretensión procesal administrativa determina el alcance, naturaleza y límites del pronunciamiento final que concluirá el juicio, mientras los puntos petitorios se contraen a asuntos de mero trámite, su inclusión es conveniente, más no obligatoria. En tanto que sin pretensión no hay proceso.

Generalmente los puntos petitorios se identifican con determinadas obligaciones que el juzgador tiene al recibir la demanda, por lo que como ya lo apuntaba no son necesarios para proceder.

\section{ESTRUCTURA DE LA PRETENSIÓN PROCESAL ADMINISTRATIVA}

La estructura de la pretensión procesal podemos derivarla del concepto que sobre la misma, aporta Guasp ${ }^{11}$ : "Es una declaración de voluntad por la que se solicita una actuación de un órgano jurisdiccional frente a persona determinada y distinta del autor de la declaración. "De lo que inferimos que está conformada por los siguientes tres elementos:

\footnotetext{
${ }^{9}$ Derecho Procesal Administrativo. Cit. p. 151.

${ }^{10}$ Supra Ibidem.

${ }^{11}$ Guasp, J. La Pretensión. Cit. p. 217. 
1. Elemento subjetivo o "entes personales que figuran como titulares, aunque en grado diferente, de las conductas humanas significativas que lleva consigo toda pretensión procesal." ${ }^{\prime 2}$

- Sujeto activo o persona que formula la reclamación.

- Sujeto pasivo o persona frente a quien se formula la reclamación

- Destinatario u órgano ante quien se formula la reclamación y debe satisfacerla

2. Elemento subjetivo o "sustrato material sobre el que recaen aquellas conductas humanas y que integran el soporte básico situado más allá de cada persona actuante y de cada actuación personal,"13 Por lo que este elemento será un bien de la vida apto para satisfacer las necesidades de tipo objetivo de los sujetos.

3. De la actividad o mutilación de la realidad constituido por "el hecho de que los titulares de la pretensión, al ocuparse del objeto de la misma, determinan con su conducta una modificación de la realidad." ${ }^{14}$ Se trata de la exteriorización de una conducta humana, implicando una declaración de voluntad petitoria.

Es consecuencia, la pretensión procesal de acuerdo a su estructura, es una declaración de voluntad, en virtud de la cual un sujeto reclama a otro, ante un órgano jurisdiccional, un bien de la vida, formulando en torno al mismo, una petición fundada.

\section{SUSTANTIVIDAD JURÍDICA Y CLASES DE PRETENSIÓN PROCESAL ADMINISTRATIVA}

Conforme a la doctrina y la legislación en materia de justicia administrativa, se identifican con toda claridad dos tipos de juicios: los de mera anulación, y los de plena jurisdicción. Al respecto González Pérez asienta: "Parece que la distinción ha quedado reducida a sus justos límites: partiendo de la unidad de la pretensión procesal administrativa, puede admitirse la existencia de aquellos dos tipos en función de lo que se pretende del órgano jurisdiccional, sin que haya por qué seguirse para cada uno de ellos cauces procesales distintos."15

Por el tipo de pronunciamiento, las pretensiones pueden ser:

1. De conocimiento: buscan la declaración de certeza de un derecho sea auténtico o no.

2. Ejecutivas: Buscan el cumplimiento obligatorio de compromisos.

3. Precautorias: tratan de evitar peligros futuros.

Todas las peticiones susceptibles de ser formuladas, pueden ser reducidas a dos grupos:

\footnotetext{
${ }^{12}$ Supra Ibidem. p. 68.

${ }^{13}$ Supra Ibidem, p. 69

${ }^{14}$ Ibidem. Loc. Cit.

${ }^{15}$ Cfr. González Pérez, op. cit. p. 153.
} 
1. Pretensiones de cognición o declarativas: emisión de una declaración de voluntad por el juzgador.

2. Pretensiones de ejecución: realización de una conducta física por el juzgador.

La diferencia entre ambas no corresponde al criterio tradicional de que las primeras determinan la formación de un mandato y las segundas su cumplimiento, sino al contrario según Guasp, el criterio de distinción se basa en el hecho de entender el proceso de cognición "como aquel que tiende a la emisión de una declaración de voluntad por el órgano jurisdiccional (sentencia)" ${ }^{16}$ y el proceso de ejecución "como aquel que tiende a la realización de una conducta física distinta del mero declarar." ${ }^{\prime 7}$

La pretensión de cognición es aquella en la cual, se solicita al juzgador una sentencia frente al demandado, lo que origina un proceso de cognición que concluirá con una declaración de voluntad en la que se actúa o no la pretensión de la parte. A su vez este tipo de pretensiones se clasifican en:

1. Peticiones en las que se reclama la creación, modificación o extinción de una situación jurídica.

2. Peticiones en las que se reclama la constatación de una situación jurídica.

3. Peticiones en las que se reclama la imposición de una situación jurídica.

Las pretensiones de cognición en el ámbito contencioso administrativo, a su vez se clasifican en:

1. Pretensión de plena jurisdicción: es aquella en que se solicita del Tribunal, no sólo la anulación del acto, sino el reconocimiento de una determinada situación jurídica individualizada. Las sentencias estimatorias de pretensiones de este tipo deberán contener los siguientes pronunciamientos:

- Anulación del acto impugnado.

- Reconocimiento de la situación jurídica individualizada desconocida por la Administración.

- En su caso, condena a que la Administración y cuantas medidas implique el reconocimiento del derecho subjetivo.

- En caso de que la satisfacción del derecho sea imposible, cabe la indemnización por daños y perjuicios, como remedio de carácter legal subsidiario para restaurar y paliar en la mayor medida el derecho perjudicado.

\footnotetext{
${ }^{16}$ Guasp. Op. cit. p. 77.

17 Ibidem. Loc. cit

CIENCIA JURIDICA. Departamento de Derecho. División de Derecho Política y Gobierno, Universidad de Guanajuato - Año 1, No. 2, 2012
} 
2. Pretensión de anulación: es aquella mediante la cual se solicita al órgano jurisdiccional la anulación del acto administrativo. Esto significa que no se solicita el reconocimiento de situaciones jurídica individualizadas, sino únicamente la anulación del acto combatido.

\section{CONCLUSIONES}

Primera.- La pretensión procesal administrativa es un acto, no un derecho, mediante el que se afirma la acción.

Segunda.- Para que una pretensión procesal sea admitida ante el Tribunal de lo Contencioso Administrativo o ante los juzgados administrativos municipales, es necesario que se reúnan los requisitos de fondo, forma y oportunidad que establece el Código de Procedimiento y Justicia Administrativa para el Estado y los Municipios de Guanajuato.

Tercera.- Aún cuando se dan ciertos puntos de coincidencias entre la pretensión procesal y la demanda, ambos conceptos son diferentes.

Cuarta.- Tanto la pretensión procesal como los puntos petitorios de la demanda, conllevan esencialmente una o varias peticiones, sin embargo, los dos términos tienen una connotación especial e implican distintas consecuencias.

Quinta.- Sólo serán actuadas pretensiones contempladas en el Código de Procedimiento y Justicia Administrativa para el Estado y los Municipios de Guanajuato, por el Tribunal de lo Contencioso Administrativo del Estado y los juzgados administrativos municipales.

BIBLIOGRAFÍA

ACOSTA ESTEVEZ, José B., Pretensión procesal administrativa, ejecución de sentencias y construcción jurisprudencial de la litispendencia en lo contencioso-administrativo, Promociones Publicaciones Universitarias, Barcelona 1987.

CARNELUTTI, Francesco, Instituciones del Proceso Civil, traducido por Santiago Sentís Melendo, Ediciones Jurídicas Europa-América, Buenos Aires, de la 5ta edición italiana, 1956.

DE LA OLIVA SANTOS, Andrés, Sobre el Derecho a la Tutela Jurisdiccional, Bosch, Barcelona, 1980.

DEVIS ECHANDÍA, Hernando, Nociones Generales de Derecho Procesal Civil, Aguilar, Madrid, 1966.

GONZÁLEZ PÉREZ, Jesús, Derecho Procesal Administrativo Mexicano, Porrúa, México, 1998.

El Contencioso Administrativo y la Responsabilidad del Estado, Abeledo Perrot, Buenos Aires, 1988. drid, 1992. 
GÓNGORA PIMENTEL, Genaro, Introducción al Estudio del Juicio de Amparo, Porrúa, México, 1987.

GUASP DELGADO, Jaime. La pretensión Procesal, Civitas, Madrid, 1981.

NAVA NEGRETE, Alfonso, Derecho Administrativo, UNAM, Instituto de Investigaciones Jurídicas, México, 1991.

RAMÍREZ ARCILLA, Carlos, Teoría de la Acción, Temis, Bogotá, 1969. 